\title{
Editorial
}

\section{Publicar en journals: Sísifo en pandemia}

https://doi.org/10.18566/comunica.n46.aOl

Recibido: 6 de octubre de 2021

Aceptado: 3 de noviembre de 2021

Cuando profesores universitarios de lado y lado del Atlántico, España y Latinoamérica, hacen los mismos comentarios sobre su quehacer en la investigación, es que algo similar nos está sucediendo. Esta redactora debe aclarar que su punto de vista es el de las ciencias sociales, y seguramente docentes de biotecnología o ingeniería de materiales no compartan una parte de lo que aquí se leerá. Pero para el campo de la comunicación, publicar se ha convertido en un verdadero remar en galeras desde que empezó la pandemia, una carrera de Sísifo, subiendo la piedra a la montaña una y otra vez.

En 2020, la pandemia trajo la evidencia de algo que se ha ido imponiendo, una tormenta perfecta contra la divulgación de los estudios sociales: cada vez los fondos para la investigación eran más difíciles de conseguir; las revistas incluían pagos, a veces muy altos, y la producción investigadora era reconocida solo con publicaciones de alta indexación.

Se trata de una tormenta perfecta que plantea una paradoja evidente: pagar por publicar una investigación por la que no se reciben ayudas y ser castigados por no hacerlo en esas caras revistas. Pongamos un ejemplo: una de las dos revistas españolas de comunicación reconocidas en el Web of Science (JCR), El Profesional de la Información, pasó de cobrar en 2020 300 euros (1.300.000 pesos) a cobrar en 2021 casi 3000 (13.000.000 de pesos) por publicar. Y no es el único caso: estas tasas de casi 3000 dólares son habituales en las revistas bien indexadas.

Estos journals son de conglomerados de empresas privadas, casi siempre anglosajonas, que controlan también los sistemas de citas; así surge un círculo cerrado al que tenemos pocas bazas para optar. Un reciente estudio de la Aneca (Agencia Nacional de Evaluación de la Calidad y Acreditación), de España, afirma que en 2020 siete de estas editoriales ingresaron 473 millones de euros por cargos a la autoría. Ellas han establecido otra

\section{Dra. Carme Ferré-Pavia} Universidad Autónoma de Barcelona carme.ferre@uab.cat http://orcid.org/0000-00027258-6376
1 Puede ir a www. aneca.es/content/ download/16664/202231/ file/210930_Openaccess.pdf 
paradoja: para publicar en abierto, es decir, cediendo nuestro esfuerzo y datos conseguidos, hay que abonar más. En realidad, pagar la cuota para poder ser citado con más asiduidad.

La perversión del sistema es bastante evidente, y las soluciones, pocas. Las universidades han fijado sistemas de ayudas a la publicación para su profesorado, pero ante el alud de demandas, no es tarea fácil conseguirlo. La política del creative commons, el open access y la transparencia de datos se ve gravemente comprometida.

A día en que se escribe, 341 personas han firmado en Colombia (1092 en España) la Declaración de San Francisco o Dora (Declaration on Research Assessment), ${ }^{2}$ a la que esta revista está adherida y que desde 2013 denuncia el sesgo en la consideración de la excelencia investigativa que se rige según el prestigio conseguido por el contenedor y no por la calidad de la investigación misma. Se pone en cuestión desde diferentes vías la consideración del factor de impacto (difusión y citas de los trabajos) que marca el ranking de esos journals.

Pero este artículo escapa al solo hecho de la perversión de la evaluación sobre la excelencia investigadora, y plantea otra dificultad: la dedicación a la investigación, que ha de equilibrar horario junto con docencia y gestión (por ejemplo, el modelo UAB es 40 \% docencia, 40 \% investigación y 20 \% gestión). También a lado y lado del Atlántico concluimos que la docencia y gestión docente en pandemia nos supuso cuadruplicar esfuerzos, con lo que investigar y esforzarse en publicar ha sido todavía más complicado y extenuante.

En el ámbito de la firmante, algunos han tirado la toalla: algunos cercanos a la jubilación, otros que reciben ingresos por otro lado, o los que simplemente reniegan de todo lo que acarrea ante lo poco que se consigue. Quizás estemos llegando a otros escenarios más conscientes de la presión insostenible de este sistema, o quizás falte tiempo para el colapso; pero lo cierto es que en entornos de gran exigencia administrativa (o llámenlo burocracia extrema), con gestiones muy dedicadas, reconocidas o no, el tiempo para la investigación escasea.

Universidades, departamentos, grupos de investigación y docentes son evaluados a través de un sistema que ha evidenciado múltiples incongruencias. Hasta entonces, parece que faltan unos años para que Dora sea difundida, con ese u otros nombres o con otras iniciativas, y que si no renunciamos por el camino, la piedra de Sísifo habrá que continuar aupándola a nuestras montañas.
2 Puede ir a https://sfdora. $\mathrm{org} / \mathrm{read} / \mathrm{read}$-the-declarationespanol/ 